\title{
LA REFORMA TRIBUTARIA 2009 EN NICARAGUA: UNA VISIÓN JURÍDICA92
}

\author{
Dr. Reynaldo Balladares Saballos 93 \\ Profesor de Derecho Universidad Centroamericana \\ Correo electrónico: balladares@usal.es
}

\begin{abstract}
Resumen: La reforma tributaria del año 2009 obedece a criterios fundamentalmente recaudatorios, más que de justicia. Significa un quebrantamiento de la lógica inherente a la tributación que encuentra en los principios de justicia tributaria el límite de legitimidad constitucional al ejercicio del poder tributario por parte del Estado para la creación de tributos o su reforma. En relación con el impuesto sobre la renta referido a las personas físicas o al pago mínimo definitivo, la regulación legal del mismo operada por la reforma en cuestión es incongruente con las exigencias de los principios de igualdad y capacidad contributiva establecidos en los artículos 114 y 115 de la Constitución nicaragüense.
\end{abstract}

Riassunto: La riforma tributaria dell'anno 2009 obedisce, fondamentalmente, a criteri di riscossione, invece di giustizia costituzionale. Significa una spazzatura della logica propria della imposizione che trova nei principi della giustizia tributaria i limiti della legittimità costituzionale all `utilizzo del potere tributario dallo Stato con riguardo alla creazione dei tributi, sebbene, alla loro riforma. In rapporto con l'imposta sul redito delle persone fisiche o al pagamento minimo definitivo, la regolazione legale dei medesimi operata dal legislatore nella suddetta riforma non è congrua nei confronti delle esigenze divenuti dai principi di eguaglianza e capacità contributiva definiti dal dettato costituzionali negli articoli 114 e 115 della Costituzione nicaraguese.

Abstract : Nicaraguan tax reform in 2009 responds basically to revenue criteria instead of justice criteria. It means a break out of the constitutional framework that finds in the tax justice principles the limits of the use of tax powers regarded to create or to reform such elements. The ability to pay and equality principles established at articles 114 and 115 of the Nicaraguan Constitution were not followed by the legal reform of the personal income tax.

92 El presente artículo constituye el resultado de la investigación presentada en el V Congreso Interdisciplinario de Investigación realizado en la Universidad Centroamericana los días 12 y 13 de mayo de 2011.

93 Licenciado en Derecho por la Universidad Centroamericana (2000). Doctor Europeo por la Universidad de Salamanca por el área científica de Derecho Financiero y Tributario (2006). Profesor de Derecho Tributario de la Universidad Centroamericana. Abogado y Notario Público.balladares@ns.uca.edu.ni 
Palabras clave: reforma / tributario, principios / Constitución / Nicaragua igualdad / capacidad contributiva / impuesto sobre la renta.

Parole chiavi: riforma / tributario / principi / Costituzione / Nicaragua eguaglianza / capacità contributiva / imposta sul redito.

Key words: tax reform, principles, Constitution, Nicaragua, equality, ability to pay, income tax

Tabla de Contenido: I. Introducción y antecedentes; II. Criterios jurídicos para una reforma fiscal: neoconstitucionalismo y principialismo tributario; 1. Los principios de justicia tributaria formal, 1.1. Legalidad, 1.2. Seguridad Jurídica, 1.3. Reserva de Ley, 2. Los principios de justicia tributaria material, 2.1. Igualdad y capacidad contributiva, 2.2. Progresividad, 3. Principales aspectos de la reforma tributaria 2009 sujetos a examen, 3.1. Impuesto sobre la renta, 3.2. Supuestos de renta ocasional, art. 6 de la ley de equidad fiscal, 3.3. Pago mínimo definitivo, III. Conclusiones; IV. Listado de referencias bibliográficas.

\section{Introducción y antecedentes}

A lo largo del segundo semestre del año 2009 se gestó en Nicaragua la realización de una reforma tributaria que supusiese el reacomodo del sistema de tributos nacionales con la mira puesta, fundamentalmente, en cubrir el déficit presupuestario crónico de las finanzas públicas nicaragüenses.

Las aportaciones y debates sobre la materia fueron expuestos desde diversos puntos de vista por parte de los actores sociales, no obstante la discusión de algunos detalles del documento se diese a lo largo diversas jornadas que, en petit comité, realizasen el Poder Ejecutivo y el Consejo Superior de la Empresa Privada (COSEP) de Nicaragua.

El ejercicio de presentación de la propuesta de reforma tributaria hecha en un hotel capitalino por las partes antes señaladas, partió de una presentación del proyecto en power point a los invitados, cuyas filminas fueron posteriormente filtradas a la prensa nacional y demás actores sociales quienes, sobre la base de tan restringida información, procedieron a realizar sus aportaciones.

Posteriormente, una vez presentado mediante tal mecanismo la propuesta de reforma, ésta fue presentada ante la Secretaría de la Asamblea Nacional de la República de Nicaragua como proyecto de "Ley de Concertación Tributaria" el que suscitó de parte de los actores políticos parlamentarios profundas discrepancias que surgieron, principalmente, del sector privado del país representado en el 
COSEP, que en pocas palabras adujo una profunda diferencia entre el proyecto presentado en las filminas de power point y los 316 artículos que conformaban el proyecto de ley presentado a la Asamblea.

La oposición política demostrada en el parlamento nicaragüense obligó a redimensionar los alcances de la reforma tributaria inicialmente planteada medianteuna renegociación entreelpoder ejecutivoeimportantes representantes de la empresa privada. Los resultados de tal negociación, llevados a cabo un día viernes, fueron presentados a la Secretaría de la Asamblea Nacional el día martes de la semana siguiente, y aprobados como ley de la República dos días más tarde.

Así pues, luego de un semestre de discusiones sobre los alcances de la reforma tributaria en 2009, el resultado fue la presentación de un proyecto de "Ley de Concertación Tributaria" actualmente inmerso en las diversas fases del proceso de formación de ley, propuesta que posteriormente fue abandonada por un proyecto nuevo, negociado y aprobado en menos de una semana, a cuyas resultas nació la Ley 712, Ley de reformas y adiciones a la Ley No. 453, Ley de Equidad Fiscal y a la Ley No. 528, Ley de reformas y adiciones a la Ley de Equidad Fiscal, publicada en la Gaceta, diario oficial, No. 241 del 21 de Diciembre de 2009.

Así pues, la presente investigación tomará como objeto de estudio los principales aspectos regulados por la ley 712, vistos desde el prisma de los derechos y garantías de los contribuyentes acuñados en el dictado de la Constitución y representados en el conjunto de principios de justicia tributaria material y formal.

\section{Criterios jurídicos para una reforma tributaria: neoconstitucionalismo y principialismo}

Toda reforma tributaria obedece a la necesidad normativa de reconducir los lineamientos jurídicos que fundan el sistema de tributos sobre la base de necesidades coyunturales de envergadura diversa que deberán ser valoradas en su justa dimensión según el espacio y tiempo en que se presenten. Buen ejemplo de ello fue, por ejemplo, el nacimiento del primer Código tributario tal y como modernamente se concibe, es decir, la Ordenanza Tributaria Alemana de 1919: las indemnizaciones a que fue sujeta la Alemania vencida de la primera guerra mundial en el Tratado de Versalles obligaron al Estado germano a reconstruir su sistema tributario, por cuanto a la fecha de tal acontecimiento cada uno de los hoy Estados federados (länder) poseía un sistema de tributos propios, así pues, la tarea encomendada a Enno Becker dio como resultado la creación de un código u "Ordenanza" que significó la derogación de una legislación dispersa, la 
unificación de las reglas generales de aplicación de tributos y la asunción de las tareas de indemnización por parte de todos los contribuyentes alemanes. Una vez más la Historia como Maestra del Derecho (Cassese, 1990; Cipollina, 1995; Gerloff, 1961; Paulick, 1980; Palao Taboada, 1980; Tipke, 1977 \& Vogel, 1968).

Es en esta lógica que se enmarca la reforma tributaria nicaragüense del año 2009: frente a un acuciante y reiterativo déficit fiscal, se hace necesario reconducir el sistema de tributos para paliar de alguna forma tal situación, agudizada además por las crisis económica mundial y el retiro de donantes internacionales que contribuían directamente con sus aportaciones al presupuesto general de la República.

Ahora bien, frente a este estado de cosas es necesario recordar que toda reforma tributaria supone, al final del camino, el ejercicio por parte del Estado del poder que constitucionalmente dispone a efectos de modificar o derogar tributos. El ejercicio de estas potestades, resumidas en la categoría del poder tributario, no es irrestricta, sino que encuentra en la misma Constitución de la que toma vida el conjunto de límites que frenan la posible incursión del Estado en el conjunto de derechos y garantías de los contribuyentes (Alexy, 2000a, Amatucci, 2004; Balladares Saballos, 2002; Barquero Esteban, 2002; Böckenförde, 2000; Canotilho, 1999; Cassese, 1990; Cossio Díaz, 1989; Fichera, 1973; Herrera Molina, 1998; Palao Taboada, 1988 \& Lago Montero, 2000).

Partimos entonces de una concepción de la Constitución como norma suprema que da origen al poder tributario del Estado, entendido como potestad para crear y aplicar tributos, a la vez que como determinante del conjunto de límites al ejercicio de tal poder, es decir, los principios de justicia tributaria (Micheli, 1967).

Esto nos sitúa frente a dos premisas de análisis de la reforma tributaria 2009 de gran envergadura:

1. La Constitución política como norma.

2. Los principios de justicia tributaria.

En relación con la primera de estas premisas es menester recalcar el carácter normativo de la Constitución, es decir, la Constitución es una norma jurídica vinculante de actuación y aplicación directa, de la misma forma que lo son normas de rango inferior como el Código Penal o la propia Ley de Equidad Fiscal. La característica que signa a esta norma es su superioridad en el ordenamiento jurídico frente a las de rango inferior, mas tal rasgo no puede llevarnos a la 
conclusión que, dado su alto nivel de abstracción y generalidad, algunas de sus disposiciones no son jurídicamente vinculantes (Abendroth, 1986; Alexy, 2002a; Amatucci, 2001; Bobbio, 1977, 1984; Canotilho, 1999; Cotarelo, 1990; De Cabo Martín, 1986; García-Pelayo, 1985; Garrorena González, 1987; González Navarro, 1992; Leibholz, 1984; Lucas Verdú, 1983; Martínez Tapia, 2000; Micheli, 1975a \& Yebra Martul-Ortega, 2004).

Así pues, hoy en días se han abandonado las tesis que pregonaban que la Constitución era una norma de plena eficacia jurídica en aquella sección "orgánica" que delimita la organización del Estado y el haz de competencias públicas, mientras que la parte "dogmática" vendría a ser no más un catálogo de buenas intenciones cuya concreción no significaría otra cosa más que el resultado de la buena voluntad política de los legisladores y gobernantes.

Superado este estado de cosas -hace poco más de 50 años-, la doctrina moderna de forma prácticamente unánime reconoce el valor normativo de la Constitución, su eficacia y aplicación directa para la resolución de casos en concreto, la consideración de todas y cada una de sus disposiciones con el vigor y fuerza vinculante inherente a cualquier norma jurídica, en definitiva, el reconocimiento de un contenido sustancial en la letra del dictado constitucional que va más allá de la organización del Estado y sus competencias públicas, y determina un conjunto de derechos, garantías, valores y principios cuya puesta en práctica supone la concreción material de fines sustantivos que operan en la lógica de la realización del bien común, por parte del Estado, en favor de los ciudadanos. Tal movimiento es hoy en día conocido como Neoconstitucionalismo (Barberis, 2000 \& Canotilho, 1999).

En este marco conceptual, los principios constituyen normas jurídicas de rango constitucional que, en el plano tributario, suponen para los contribuyentes un haz de derechos y garantías que limita el actuar del Estado en el uso de su, también constitucional, poder tributario, el cual se manifestará en la creación y aplicación de tributos o, en el caso que nos ocupa, la reforma tributaria de 2009 (Alexy, 2000a; Gallego Peragón, 2003; García, Etchegoyen, 2004; Palao Taboada, 1995; Pérez de Ayala, 1979; Prieto Sanchís, 1998 \& Vidal Marín, 2003).

Llegados a este punto, es menester referirnos a la segunda premisa antes acotada, es decir, los principios de justicia tributaria. Entendidos como normas que se encuentran en la Constitución, modernamentelos principios se conceptúan como mandatos de optimización condicionados por las circunstancias o condiciones fácticas y jurídicas, es decir, son normas que imponen que "algo" deba realizarse de la mejor o mayor manera posible, en cuyo marco de actuación el grado de cumplimiento de ese "algo" se encuentra condicionado por las circunstancias 
del entorno que nos rodea, o bien por las normas jurídicas preexistentes que sirven para delimitar, como en un juego de contrarios, el ámbito jurídico de actuación de tal principio (Alexy, 2000a; Alexy, 200ob; Bernal Pulido, 2003 \& González Beilfuss, 2003).

En el caso que nos ocupa, los principios que sirven a realizar la idea de justicia en el ámbito tributario encuentran asidero en nuestra Constitución. Ello no podría ser de otra manera en tanto que en el mismo ámbito constitucional se crea y da origen al poder tributario del Estado. Así pues, el juego de contrarios en el ámbito tributario se desarrolla en el máximo ámbito de superioridad jurídica: el plano constitucional (Alguacil Marí, 1999; Amatucci, 2001; Crisafulli, 1965; De Juan Asenjo, 1984; Fichera, 2002; Gaffuri, 1969; González García, 1996; Lago Montero, 2000; Herrera Molina, 1998; Mafezzoni, 1970; Manzoni, 1965; Micheli, 1973; Tipke, 2002 \& Yebra Martul-Ortega, 2004).

La justicia tributaria no será otra cosa más que la implementación del conjunto de principios de justicia tributaria, mismos que deberán hacerse patente en la estructuración de los tributos. De ahí quela creación de tributos, o su modificación a través de una reforma como la que es objeto de estudio del presente trabajo, deba pasar por el filtro de tales principios a efectos de delimitar su legitimidad constitucional (Alguacil Marí, 1995; Amatucci, 1965; Carmona Cuenca, 1994, 2000; Casado Ollero, 1982; Crisafulli, 1959: Crisafulli, 1965; Escribano López, 1989; Ferreiro Lapatza, 2001; Gallego Peragón, 2003; García Etchegoyen, 2004; Guervós Maíllo, 2000; Herrera Molina, 1998, Lago Montero, 2000; Maffezzoni, 1970; Manzoni, 1965; Micheli, 1967a, 1967b, 1967c; Moschetti, 1973; Palao Taboada, 1976; Pérez de Ayala, 1997 \& Sainz de Bujanda, 1963).

El esfuerzo jurídico a realizar en sede jurídico tributaria a efectos de valorar la legitimidad constitucional de cualquier reforma tributaria supone, entonces, analizar la reforma de las estructuras de los tributos reformados a la luz del contenido esencial de los principios de justicia tributaria. Tal contenido esencial es ese "algo" al que nos referíamos al definir qué es un principio, y variará según el principio del cual estemos hablando (Alexy, 2000a; Alexy, 200ob; Bernal Pulido, 2003; González Beilfuss, 2003 \& Ferreiro Lapatza, 2001).

Dicho esto, el conjunto de principios de justicia tributaria suele presentarse, con efectos meramente didácticos, dividido en dos grandes ámbitos: principios de justicia tributaria formal, y principios de justicia tributaria material. Los primeros hacen referencia al modo en el cual deben ser creados los tributos, o bien cómo deben nacer a la vida jurídica -fundamentalmente a través de una norma con rango de ley-, mientras que los segundos nos refieren al contenido de la prestación tributaria, es decir, riqueza apta para el sufragio de los gastos 
públicos, o lo que es lo mismo, capacidad contributiva (Amatucci, 2001; Balladares Saballos, 2002; Gallego Peragón, 2003; Vidal Marín, 2003 \& Yebra Martul-Ortega, 2004).

Cada uno de tales principios, en su respectivo ámbito, constituye un límite al ejercicio del poder tributario. De faltarse al cumplimiento de cualquiera de ellos en la estructuración de cualquier tributo, estaríamos en presencia de una prestación constitucionalmente ilegítima. Dicho en términos más sencillos: los principios de justicia tributaria son los ingredientes de un plato final llamado tributo, si falta uno de ellos lo que tendremos en nuestra presencia será cualquier cosa, menos un tributo (Amatucci, 2001; Balladares Saballos, 2007; Ferreiro Lapatza, 2001; Guervós Maíllo, 2000 \& Herrera Molina, 1998).

El ejercicio al que se somete cualquier tributo -de nuevo cuño, o reformado como es el caso que nos ocupa- supone entonces analizar si las exigencias de cada uno de los principios de justicia tributaria se hace patente en la estructuración del tributo recién nacido a la vida jurídica o reformado. Tal método se denomina principialismo (Alexy, 2000a; Amatucci, 1975; Barberis, 2000; Casado Ollero, 1982; Fichera, 2002; Gallego Peragón, 2003; García-Pelayo, 1975; González Beilfuss, 2003; González García, 1993; Guervós Maíllo, 2000; Herrera Molina, 1998; Lago Montero, 2000; Micheli, 1975a; Palao Taboada, 1995; Pérez de Ayala, 1979; Prieto Sanchís, 1998; Vidal Marín, 2003 \& Yebra Martul-Ortega, 2004).

En Nicaragua, nuestra Constitución regula de forma abstracta cada uno de los principios depurados por la ciencia jurídico tributaria para la búsqueda de la justicia en este ámbito. El arto. 114 establece que:

Corresponde exclusivamente y de forma indelegable a la Asamblea Nacional la potestad para crear, aprobar, modificar o suprimir tributos. El Sistema Tributario debe tomar en consideración la distribución de la riqueza y de las rentas.

Se prohíben los tributos o impuestos de carácter confiscatorio.

Estarán exentas del pago de toda clase de impuesto los medicamentos, vacunas y sueros de consumo humano, órtesis y prótesis; lo mismo que los insumos y materia prima necesarios para la elaboración de esos productos, de conformidad con la clasificación y procedimientos que se establezcan. 
El arto. 115 por su parte, afirma que:

"Los impuestos deben ser creador por ley que establezca su incidencia, tipo impositivo y las garantías de los contribuyentes. El Estado no obligará a pagar impuestos que previamente no estén establecidos en una ley.”

Una interpretación sistemática de los preceptos nos lleva a la primera conclusión de que entre ambas normas existe un nexo de complementariedad que no puede escindirse al momento de desentrañar el significado de los mismos. A nuestro modo de ver, ambas cláusulas constitucionales acogen el sistema de principios de justicia tributaria, aunque el dictado literal de la norma no haga expresa mención de ellos (Balladares Saballos, 2007).

Consecuentemente, y en segundo término, cabe señalar que una interpretación sistemática del precepto arroja como resultado que la actividad impositiva del Estado debe ejercerse atendiendo a la justicia tributaria (Balladares Saballos, 2007).

Cabe señalar que los principios de justicia tributaria, en unas ocasiones, se encuentran expresamente contenidos en la Constitución y en otras se deducen mediante interpretación de la norma constitucional. El primero de los casos es el español cuyo art. 31.1 establece que "todos contribuirán al sostenimiento de los gastos públicos de acuerdo con su capacidad económica mediante un sistema tributario justo inspirado en los principios de igualdad y progresividad que, en ningún caso, tendrá alcance confiscatorio”, o bien el italiano, cuyo art. 53 de la Constitución italiana establece que "todos son llamados a contribuir a los gastos públicos en razón de la capacidad contributiva” (Balladares Saballos, 2007).

Por otra parte, ejemplo de principios cuya existencia se deduce mediante interpretación es el alemán, cuya rica jurisprudencia en materia de principios de justicia tributaria material nace de la interpretación que tanto el Tribunal Constitucional como la doctrina han realizado del art. 3 GG que, sucintamente, establece que "Todos los alemanes son iguales ante la ley". Así, del principio de igualdad se derivan una serie de exigencias y principios tributarios -como el de capacidad contributiva- que irradian al espectro europeo tributario más próximo los esquemas conceptuales tributarios germánico-latinos que nosotros mismos compartimos (Balladares Saballos, 2007).

El caso nicaragüense entra en esta última situación. Aunque nuestra Constitución sea parca en cuanto al establecimiento de principios de justicia tributaria de modo expreso, ello no implica que desde una perspectiva exclusivamente jurídica no puedan deducirse del dictado constitucional tales mandatos. 
Así pues, la carencia de principios de justicia tributaria expresamente acuñados en el texto constitucional en nada impide que mediante una interpretación sistemática basada en la jurisprudencia y doctrina comparada puedan acogerse tales mandatos, claros de que tal parquedad impone la exégesis de la norma constitucional en aras de contribuir a la justicia tributaria en la creación de los impuestos.

De lo anterior, y en definitiva, se deduce que el conjunto de buena parte de los principios de justicia fiscal largamente depurado por la ciencia jurídicotributaria serán producto, en nuestra Constitución, de la labor interpretativa constitucional (Amatucci, 1965; Barberis, 2000; Cayón Galiardo, 1988; Fichera, 1973a; Herrera Molina; 1998; Lozano Serrano, 1990; Palao Taboada, 1988; Paulick, 1980; Prieto Sanchís, 1998; Rodríguez Bereijo, 1992; Sainz de Bujanda, 1963 \& Yebra Martul-Ortega, 2004).

Así pues, cabe deducirse de nuestra Constitución que los principios acuñados en nuestro sistema son:

Principios de justicia tributaria formal:

Legalidad

Seguridad Jurídica

Reserva de ley

Principios de justicia tributaria material:

Generalidad

Igualdad

Capacidad Contributiva

Progresividad

No confiscatoriedad

1. Los principios de justicia tributaria formal

\subsection{Legalidad}

El principio de legalidad en materia tributaria se encuentra inserto en nuestro ordenamiento jurídico en los arts. 114, 115 y 138.27 Cn., así como 3 CTr.

En su concepción más restringida, el principio de legalidad implica que sólo mediante ley pueden ser impuestos por el Estado sacrificios patrimoniales a los ciudadanos (González García \& Lejeune Valcárcel, 2000). 
El precepto inspira, por una parte, el principio de autoimposición, mejor conocido en el constitucionalismo como no taxation without representation, o en el mundo romano, como "lo que a todos afecta, por todos debe ser aprobado" (González García \& Lejeune Valcárcel, 2000).

\subsection{Seguridad Jurídica}

De la legalidad se infiere la certeza y objetividad de la norma tributaria, así como la prohibición o la interdicción de la arbitrariedad en materia tributaria. Estas características constituyen el filón material del principio de seguridad jurídica, otorgándole coherentemente, su ámbito y vía de manifestación. Así pues, la seguridad jurídica constituye un aspecto que completa las notas cualificativas del principio de legalidad (González García \& Lejeune Valcárcel, 2000).

En su aspecto positivo, el principio de seguridad jurídica determina que la ley debe constituir un vehículo generador de certeza jurídica, es decir, aquello que en un plano vulgo se identifica con "saber a qué atenerse", mientras que en su aspecto negativo sitúa a la ley como mecanismo de defensa frente a las posibles arbitrariedades de los órganos del Estado (González García \& Lejeune Valcárcel, 2000).

En la jurisprudencia comparada, por ejemplo, del Tribunal Constitucional español -sentencia 27/1981, FJ $10^{\circ}$ - el principio de seguridad jurídica se aplica en una triple dimensión:

1. Como conocimiento y certeza del Derecho positivo,

2. Como confianza de los ciudadanos en las instituciones públicas y en el orden jurídico en general, en cuanto garantes de la paz social, y

3. Como previsibilidad, de los efectos que se derivan de la aplicación de las normas y de las propias acciones o de las conductas de terceros.

Así pues, este Tribunal aclara mediante sentencia 46/1990, que

El legislador debe perseguir la claridad y no la confusión normativa, debe procurar que acerca de la materia sobre la que se legisle sepan los operadores jurídicos a qué atenerse y debe huir de provocar situaciones objetivamente confusas (...), como consecuencia de las cuales se introducen perplejidades difícilmente salvables respecto a la previsibilidad de cuál sea el Derecho aplicable, cuáles las consecuencias derivadas de las normas vigentes, incluso cuáles sean éstas. 
Esto evidencia, por ejemplo, que en tal jurisprudencia comparada el contenido del principio de legalidad en materia tributaria sea la suma de certeza, jerarquía y publicidad normativa, irretroactividad de lo no favorable e interdicción de la arbitrariedad, sin perjuicio del valor que por sí mismo tiene aquel principio Ya por último a través de sentencia 150/1990, FJ $8^{\circ}$ asume este alto tribunal que:

Los principios de seguridad jurídica y de interdicción de la arbitrariedad de los poderes públicos exigen que la norma sea clara para que los ciudadanos sepan a qué atenerse ante la misma, en este orden de exigencia no cabe subestimar la importancia que para la certeza del Derecho y la seguridad jurídica tiene el empleo de una depurada técnica jurídica en el proceso de elaboración de las normas, singularmente en un sector como el tributario, que, además de regular actos y relaciones jurídicas en masa que afectan y condicionan la actividad económica global de todos los ciudadanos, atribuye a éstos una participación y un protagonismo creciente en la gestión y aplicación de los tributos. Resulta inexcusable en este contexto el esfuerzo del legislador (...) por alumbrar una normativa tributaria abarcable y comprensible para la mayoría de los ciudadanos a los que va dirigida; puesto que una legislación confusa, oscura e incompleta dificulta su aplicación y, además de socavar la certeza del Derecho y la confianza de los ciudadanos en el mismo, puede terminar por empañar el valor de la justicia.

\subsection{Reserva de Ley}

$\mathrm{Al}$ acometer el estudio de este principio es necesario aclara el doble sentido que encarna. De una parte, y en sentido positivo, implica que sólo la ley tiene cabida en la creación de los diversos elementos constitutivos del tributo, en detrimento de las demás fuentes del Derecho de rango inferior (González García \& Lejeune Valcárcel, 2000).

En sentido negativo, la reserva de ley impone la reserva de la potestad de crear, modificar o suprimir tributos a la Asamblea Nacional de la República, excluyendo en todo caso, la intromisión de cualquier otro poder del Estado en la creación de tributos, o la posible creación de los mismos por parte de los Municipios (Balladares Saballos, 2007; González García \& Lejeune Valcárcel, 2000)

El alcance de cuáles de los elementos deben formar parte de la ley que instaura el tributo, ha dado origen en la doctrina a la consideración de la reserva de ley absoluta, o relativa. Ésta última implica la regulación por ley de algunos elementos básicos de la obligación, tales como sujeto activo, sujeto pasivo y hecho imponible, previendo el desarrollo legislativo del resto de elementos a 
través de normas de rango inferior al legal (Balladares Saballos, 2007; Guervós Maíllo; Lago Montero, 2000).

Nuestro ordenamiento jurídico no establece a nivel constitucional tal exigencia, sino que es a través del art. $115 \mathrm{Cn}$, y $3 \mathrm{CTr}$. que se acota el alcance del principio, dotando a nuestra reserva de ley de carácter absoluto. En este sentido, nuestra legislación impone como exigencia devenida de la Constitución que sólo mediante ley se podrá:

1. Crear, aprobar, modificar o derogar tributos;

2. Otorgar, modificar, ampliar o eliminar exenciones, exoneraciones, condonaciones y demás beneficios tributarios;

3. Definir el hecho generador de la obligación tributaria; establecer el sujeto pasivo del tributo como contribuyente o responsable; la responsabilidad solidaria, así como fijar la base imponible y la alícuota aplicable (tipo de gravamen).

4. Establecer y modificar las preferencias y garantías para las obligaciones tributarias y derechos del Contribuyente, y

5. Definir las infracciones, los delitos y las respectivas sanciones.

\section{Los principios de justicia tributaria material}

En lo que sigue haremos referencia a los principios de justicia tributaria material, no obstante quepa señalar las siguientes premisas de análisis (González García \& Lejeune Valcárcel, 2000):

1) Capacidad contributiva, igualdad y progresividad no son tres principios diferentes, sino explicitaciones del principio básico de igualdad en su acepción de igualdad material, e igualdad formal. (arts. 27 y $48 \mathrm{Cn}$.)

2) La generalidad se imbuye también en el ámbito de acción del principio de igualdad, como una explicitación más del mismo.

3) La no confiscatoriedad no es un principio autónomo de justicia tributaria, sino una exigencia derivada de la protección constitucional de la propiedad privada, actuando al mismo tiempo, como límite de la progresividad tributaria. (Arto. 44 Cn.).

\subsection{Igualdad y capacidad contributiva}

Hemos de iniciar el tratamiento de los principios de igualdad y capacidad contributiva haciendo una breve referencia al principio de generalidad. Comprendemos que el principio de generalidad se encuentra contenido entre 
las notas conceptuales del principio básico de igualdad, y acuñado en el arto. 115 Cn. al establecer la obligación de crear los tributos mediante ley.

El principio de generalidad no está tanto dirigido a ordenar que todos deben contribuir a la financiación de las cargas públicas, cuanto a prohibir las exclusiones apriorísticas de cualquier tipo de personas, es decir, a erradicar toda clase de privilegios e inmunidades fiscales. De ahí que un recto entendimiento de este principio exige conectarlo con otro: el de capacidad contributiva, de forma que solo aquellos que tengan tal capacidad pueden considerarse incluidos dentro de la obligación constitucional de sostener los gastos públicos, lo que convierte a éste en el principio rector de nuestro ordenamiento tributario (González García \& Lejeune Valcárcel, 2000).

Ya en relación directa con el principio de la igualdad, la doctrina (Alguacil Marí, 2009; Amatucci, 1975; Canotilho, 1999; Carmona Cuenca, 1994, 2000; Casado Ollero, 1982; Crisafulli, 1959 y 1965; Escribano López, 1989; Fichera, 1973b; Gaffuri, 1969; Gallego Peragón, 2003; García Etchegoyen, 2004; Giardina, 1961; González García, 1993; Herrera Molina, 1998; Lombardo, 1997; Lozano Serrano, 1990; Maffezzoni, 1970; Manzoni, 1965; Martínez Tapia, 2000; Micheli, 1967a, 1967b, 1967c; Moschetti, 1973; Palao Taboada, 1995, 1988, 1976; Pérez de Ayala, 1979; Rodríguez Bereijo, 1992; Tipke, 2002, 1977; Vidal Marín, 2003; Vogel, 1968; Yebra Martul-Ortega, 2004) y la jurisprudencia española a través de la sentencia No. 79 de 1990, fundamento jurídico $9^{\circ} \mathrm{A}$, resumen al contenido del principio de igualdad según las notas siguientes:

1. No toda desigualad de trato en la ley supone una infracción de la igualdad constitucional, sino que dicha infracción la produce sólo aquella desigualdad que introduce una diferencia entre situaciones que pueden considerarse iguales y que carece de una justificación objetiva y razonable;

2. El principio de igualdad exige que a iguales supuestos de hecho se apliquen iguales consecuencias jurídicas, debiendo considerarse iguales dos supuestos de hecho cuando la utilización o introducción de elementos diferenciadores sea arbitraria o carezca de fundamento racional;

3. El principio de igualdad no prohíbe al legislador cualquier desigualdad de trato, sino sólo aquellas desigualdades que resulten artificiosas o injustificadas por no venir fundadas en criterios objetivos y suficientemente razonables de acuerdo con criterios o juicios de valor generalmente aceptados.

Respecto a esta última nota, para que la diferenciación resulte constitucionalmente lícita no basta con que lo sea el fin que con ella se persigue, 
sino que es indispensable además que las consecuencias jurídicas que resulten de tal distinción sean adecuadas y proporcionadas a dicho fin, de manera que la relación entre la medida adoptada, el resultado que se produce y el fin pretendido por el legislador superen un juicio de proporcionalidad en sede constitucional, evitando resultados especialmente gravosos o desmedidos.

Las notas conceptuales que se aportan a través de esta sentencia bien pueden resumirse en que el principio de igualdad exige lo siguiente:

1. Las situaciones o casos iguales se tratan de forma igual, y los desiguales, de forma desigual.

2. Tal postulado puede romperse ante la existencia de un motivo justo y razonable según la naturaleza de la cosa.

Hasta este punto se construye el concepto de igualdad formal.

3. El Estado debe hacer superar las situaciones de desigualdad ilegítima entre grupos homogéneos de personas.

4. Los instrumentos que el Estado utilice para hacer realidad el postulado anterior deben ser proporcionados al fin que pretenden, esto eso, superar las exigencias del principio de proporcionalidad, el cual implica como subprincipios la idoneidad, necesidad y proporcionalidad en sentido estricto de tales instrumentos respecto del fin que persiguen.

Tales dos últimas notas realizan el concepto de igualdad material, también entendida en la literatura especializada como igualdad sustancia, promocional, prestacional o de hecho.

Ya en relación con el principio de capacidad contributiva podemos señalar que se encuentra presente en nuestra Constitución en el arto. $114 \mathrm{Cn}$., cuando establece que "el sistema tributario debe tomar en consideración la distribución de la riqueza y de las rentas".

La capacidad contributiva, por una parte es la ratio o fundamento que justifica el hecho mismo de contribuir y el cumplimiento de tal deber constitucional. Constituye el elemento indisociable del impuesto que legitima constitucionalmente el gravamen: se debe porque se tiene capacidad contributiva para soportar la carga tributaria, con lo que, en tal sentido, la capacidad contributiva presupone la aptitud para contribuir (Alguacil Marí, 2009; Amatucci, 1975; Canotilho, 1999; Carmona Cuenca, 1994, 2000; Casado Ollero, 1982; Crisafulli, 1965; Escribano López, 1989; Fichera, 1973a; Gaffuri, 1969; Gallego Peragón, 2003; García Etchegoyen, 2004; Giardina, 1961; González García, 1993; Herrera Molina, 1998; Lombardo, 1997; Lozano Serrano, 1990; Maffezzoni, 1970; Manzoni, 1965; Martínez Tapia, 2000; Micheli, 1967a, 1967b, 
1967c; Moschetti, 1973; Palao Taboada, 1995, 1988, 1976; Pérez de Ayala, 1979; Rodríguez Bereijo, 1992; Tipke, 2002, 1977; Vidal Marín, 2003; Vogel, 1968; Yebra Martul-Ortega, 2004).

En segundo término, el principio de capacidad contributiva constituye la medida, razón o proporción de cada contribución individual de los sujetos obligados al sostenimiento de los gastos públicos. Si se debe según la capacidad que se tiene, ello debe reflejarse en el hecho imponible o en los elementos esenciales que determinan la cuantificación del impuesto.

Las funciones del principio de capacidad contributiva como medida del deber de contribuir a los gastos públicos y límite para el legislador en la configuración de los impuestos obliga a tomar como presupuesto de hecho normativo circunstancias que directa o indirectamente sean reveladoras de potencia económica real y efectiva, en cualquier caso existente, es decir, no simplemente nominal o potencial (Giardina, 1961; Manzoni, 1965).

Tales funciones y significados, encuentran asidero práctico refiriendo el contenido material de la capacidad contributiva a la riqueza del contribuyente apta para el sufragio de los gastos públicos. La capacidad económica se entiende así como la idoneidad del sujeto pasivo para la contribución a los gastos públicos, la cual se pondrá en evidencia a través de su nivel de riqueza.

Tal nivel de riqueza hace necesario remitirnos a la forma en la cual se presenta la misma en el tejido económico. Usualmente, se suele referir por la doctrina que son índices de riqueza, y consecuentemente, índices de capacidad contributiva, la renta, el patrimonio y el gasto (Amatucci, 2004; Giardina, 1961; Manzoni, 1965; Moschetti, 1973).

La definición de cada uno de ellos no es cuestión pacífica ni en la doctrina, ni la jurisprudencia, ni mucho menos en el derecho comparado. Quizás ello se deba al esfuerzo de no encorsetar en una definición índices de riqueza sujetos a los vaivenes de la propia creación de la riqueza, esto es, de definirse en términos absolutos, podría dejarse fuera de la definición eventuales formas de manifestación de la misma.

En razón de lo antes dicho el criterio consensuado y aproximado acerca de la noción de cada uno de los índices de capacidad contributiva suele referir que la renta es la riqueza que se crea, bien sea por el ejercicio de una actividad económico en cuyo caso estaremos en presencia de rentas de capital, o producto del esfuerzo laboral de las personas, lo que nos referirá a rentas de trabajo. 
El patrimonio se suele referir a la riqueza que forma parte de la hacienda personal del contribuyente, entendiendo que será mucho más idóneo para el sufragio de los gastos públicos en este caso el mayor valor que el patrimonio adquiera con el paso del tiempo, aunque existan supuestos en los cuales se graven manifestaciones por relación a patrimonio que se deprecia con el paso del tiempo.

Ya por último encontramos el gasto, el cual se refiere a la riqueza que se consume en los diversos actos de la vida diaria. En este caso, el punto de mayor fricción surge respecto del tipo de gasto que se grava, así como la idoneidad misma del índice para crear sobre él impuestos. En lo que toca al primer argumento, la distinción del tipo de gasto que se realiza ha originado la existencia de diversos tipo de impuestos, que en el caso que nos ocupa, nos remiten al IVA y al ISC, gravando el primero el gasto común y ordinario, mientras que el segundo, tal y como su nombre lo indica, grava selectivamente el consumo de bienes claramente definidos por la norma en el entendimiento de que los mismos hacen referencia bienes de consumo suntuario o bien de demanda inelástica.

Así pues, esta riqueza, que es substrato lógico de la aptitud para el sostenimiento de los gastos públicos, en el esquema constitucional no es una potencialidad económica aislada que se allega por sí sola a las arcas públicas. Es un índice de idoneidad contributiva inherente a un sujeto llamado por la norma a cumplir la obligación legal de dar una suma de dinero (Alguacil Marí, 2009; Amatucci, 1975; Canotilho, 1999; Carmona Cuenca, 1994, 2000; Casado Ollero, 1982; Crisafulli, 1959 y 1965; Escribano López, 1989; Fichera, 1973b; Gaffuri, 1969; Gallego Peragón, 2003; García Etchegoyen, 2004; Giardina, 1961; González García, 1993; Herrera Molina, 1998; Lombardo, 1997; Lozano Serrano, 1990; Maffezzoni, 1970; Manzoni, 1965; Martínez Tapia, 2000; Micheli, 1967a, 1967b, 1967c; Moschetti, 1973; Palao Taboada, 1995, 1988, 1976; Pérez de Ayala, 1979; Rodríguez Bereijo, 1992; Tipke, 2002, 1977; Vidal Marín, 2003; Vogel, 1968; Yebra Martul-Ortega, 2004)

Podemos afirmar entonces con CASADO OLLERO (1982) que no basta con verificar si el hecho tipificado por el legislador es indicativo de riqueza, sino que también es preciso atender a la aptitud económica del contribuyente, esto es, al contenido relacional de la capacidad contributiva en el que se valoren los recursos disponibles y las necesidades a cubrir por el sujeto para comprobar si la exacción del impuesto resulta confiscatoria o afecta al mínimo necesario para su existencia, entendiendo que tal capacidad es un atributo del sujeto que se pone en conexión con los recursos y necesidades del mismo, y no sólo con los hechos objetivamente tipificados en el hecho imponible. De no entenderlo así se valorarían de forma banal las exigencias constitucionales de la capacidad como 
fundamento de la imposición, al considerarlas cumplidas con la tipificación de hechos de cualquier modo indicativos de potencialidad económica.

Consecuencia de lo anterior es que la capacidad para contribuir al sostenimiento de los gastos públicos sólo puede entrar en juego una vez que se hayan cubierto otras obligaciones jurídicas de carácter prioritario, entre las que, en primer lugar, se encuentra el deber de alimentos y educación. La cobertura de estos gastos no puede ser desconocida por el legislador fiscal a la hora de fijar la contribución de los ciudadanos al sostenimiento de las cargas públicas porque se encuentra recogida en los arts. 24, 59, 60, 63, 64, 65, 70, 71, 73, 77, 80, 82 $\mathrm{Cn}$. Un régimen tributario que viole estos preceptos elementales no podrá ser jurídico, ni justo (Casado Ollero, 1982; Balladares Saballos, 2007).

Con lo dicho, cabe señalar que: a) no pueden existir impuestos en ausencia de capacidad contributiva (capacidad contributiva como presupuesto de la imposición); b) en presencia de capacidad contributiva no se puede requerir al sujeto un concurso a los gastos públicos superior a aquello que su capacidad contributiva le consienta (capacidad contributiva como límite a la imposición) (Manzoni, 1965).

Pero la capacidad contributiva no juega sólo como presupuesto y límite, sino también como parámetro de la imposición operando como medida unitaria de referimiento en la determinación de la concreta carga tributaria que debe gravar a variedad de sujetos. (Manzoni, 1965).

El principio de capacidad contributiva viene así a afirmarse como principio de la igualdad tributaria, entendida no ya en el sentido que todos deban contribuir en igual medida -lo que sería absurdo- sino en el sentido que debe asegurarse uniformidad de tratamiento a paridad de condiciones, lo que a la vez significa, en otras palabras, que no pueden operarse tratamientos diferenciados referente a sujetos puestos en idénticas situaciones de capacidad contributiva $\mathrm{y}$, por el contrario, que a situaciones de capacidad contributiva diversas debe corresponder un diverso tratamiento: gravamen mayor a mayor capacidad contributiva, exacción menor a menor capacidad contributiva (Alguacil Marí, 2009; Amatucci, 1975; Canotilho, 1999; Carmona Cuenca, 1994, 2000; Casado Ollero, 1982; Crisafulli, 1959 y 1965; Escribano López, 1989; Fichera, 1973b; Gaffuri, 1969; Gallego Peragón, 2003; García Etchegoyen, 2004; Giardina, 1961; González García, 1993; Herrera Molina, 1998; Lombardo, 1997; Lozano Serrano, 1990; Maffezzoni, 1970; Manzoni, 1965; Martínez Tapia, 2000; Micheli, 1967a, 1967b, 1967c; Moschetti, 1973; Palao Taboada, 1995, 1988, 1976; Pérez de Ayala, 1979; Rodríguez Bereijo, 1992; Tipke, 2002, 1977; Vidal Marín, 2003; Vogel, 1968; Yebra Martul-Ortega, 2004). 
La conexión más evidente entre igualdad y capacidad contributiva se manifiesta a través de la sentencia italiana n. 155 de 13 de diciembre de 1963 donde la Corte Costituzionale afirma que el art. 53 de la Constitución italiana se traduce en la exigencia de imposición igual para rentas iguales e imposición diversa para rentas diversas, constituyendo de esta forma un armónico y específico desarrollo del principio de igualdad; en esta línea, el tribunal aclara mediante sentencia n. 6 del 25 de junio de 1966 que el art. 3 de la Constitución italiana debe entenderse como prohibición de disparidad de tratamiento de situaciones similares y como exclusión de discriminaciones irrazonables.

Para nosotros la capacidad contributiva no constituye un criterio que "también" sirva para determinar si dos situaciones son o no semejantes desde el punto de vista tributario, sino que es el único parámetro jurídico válido para determinar la justa incidencia del poder público en la potencia económica de los sujetos pasivos, a través de la determinación del hecho imponible y demás elementos de cuantificación del impuesto.

Hecha esta matización es posible concluir que la capacidad económica funciona como una especificación del principio de igualdad. Ello en primera instancia facilita realizar un juicio sobre la idoneidad de una determinada situación para ser objeto de imposición en función de la capacidad económica, no ya para evitar desigualdades arbitrarias (efecto negativo), sino para realizar concretamente la igualdad (efecto positivo).

A su vez, se elimina toda rigidez del concepto tradicional de capacidad contributiva, entendida como la medida de lo igual y lo desigual, y se posibilita no ya la igualdad "a través" de la capacidad económica, sino la igualdad "en" la capacidad económica.

\subsection{Progresividad}

La progresividad, en palabras de MARTÍN DELGADO (1979), constituye un criterio que inspira el ordenamiento por cuya virtud los titulares de mayor capacidad económica son gravados de forma más que proporcional en comparación con los de capacidad más baja.

Es por tanto un resultado del entero sistema tributario, el que deberá estar estructurado y concebido de forma que consiga realizarla efectivamente.

Su presencia permite la justificación teórica de los tipos progresivos que se presentan en el plano normativo del sistema tributario como criterio de reparto de las cargas públicas en aquellos impuestos cuya estructura así lo permite, 
cual es el caso del Impuesto sobre la Renta, art. 21 LEF, por ejemplo. Puesto que la capacidad contributiva crece en forma más que proporcional, es decir, progresiva, el principio de progresividad inspira el gravamen de los índices de capacidad económica conforme a tal criterio.

El contenido normativo de la progresividad en la jurisprudencia constitucional se aclara mediante sentencia n. 128 de 1966 en la que la Corte Costituzionale afirma que la norma constitucional no prohíbe que los tributos singulares sean inspirados en criterios diversos de la progresividad, sino que se limita a declarar que el sistema tributario debe tener, en su conjunto, un carácter progresivo. En verdad -en la multiplicidad y variedad de impuestos a través de los cuales viene repartida entre los ciudadanos la carga tributaria-, no todos los impuestos se prestan, desde el punto de vista técnico, a adaptarse al principio de progresividad, que -entendido en el sentido de aumento de alícuota según el crecimiento de la renta- presupone una conexión entre imposición y renta individual de cada contribuyente.

Así pues, según PÉREZ De AYALA (1979), la progresividad de un sistema fiscal consiste en que

Quien más capacidad contributiva tiene pague más que proporcionalmente que el que la tiene menos, por el conjunto de impuestos que respectivamente les graven. La progresividad de un sistema de impuestos presupone que los modelos o instituciones fiscales seleccionados para integrar aquel sistema constituyen en materias imponibles la renta total en sí misma, si bien, magnitudes que crecen más que proporcionalmente que la renta (pp. 105 y 106).

\section{Principales aspectos de la reforma tributaria 2009 sujetos a examen}

\subsection{Impuesto sobre la renta}

El impuesto sobre la renta fue objeto de reforma a través de la ley 712. Uno de los principales aspectos criticables a la luz de los principios antes reseñados es la modificación del art. 21 de la ley de equidad fiscal. Especial atención merece la creación de dos tablas progresivas para la aplicación del IR a las personas físicas, del modo que a continuación se presenta:

"Arto. 21. Alícuotas.

El impuesto establecido por la presente Ley será tasado, exigido, recaudado y pagado sobre la renta imponible del correspondiente año gravable y el monto del mismo consistirá en las sumas que resulten de acuerdo con las siguientes disposiciones: 
1. Para las personas jurídicas en general, el impuesto a pagar será el treinta por ciento de su renta imponible.

2. Para las personas naturales, el impuesto a pagar se calculará de conformidad con la tarifa progresiva siguiente:

\begin{tabular}{|c|l|l|l|r|}
\hline \multicolumn{2}{|c|}{$\begin{array}{c}\text { Renta gravable } \\
\text { (Estratos) }\end{array}$} & $\begin{array}{c}\text { Impuesto } \\
\text { base }\end{array}$ & $\begin{array}{c}\text { Porcentaje } \\
\text { aplicable }\end{array}$ & $\begin{array}{c}\text { Sobre exceso } \\
\text { de }\end{array}$ \\
\hline De C\$ & Hasta C\$ & & & \\
1.00 & $50,000.00$ & 0 & $0 \%$ & 0 \\
$50,000.01$ & $100,000.00$ & 0 & $10 \%$ & $50,000.00$ \\
$100,000.01$ & $200,000.00$ & $5,000.00$ & $15 \%$ & $100,000.00$ \\
$200,000.01$ & $300,000.00$ & $20,000.00$ & $20 \%$ & $200,000.00$ \\
$300,000.01$ & $500,000.00$ & $40,000.00$ & $25 \%$ & $300,000.00$ \\
$500,000.01$ & a más & $90,000.00$ & $30 \%$ & $500,000.00$ \\
\hline
\end{tabular}

3. Para las personas asalariadas en particular, el impuesto a pagar se calculará de conformidad con la tarifa progresiva siguiente:

\begin{tabular}{|c|l|l|l|r|}
\hline \multicolumn{2}{|c|}{$\begin{array}{c}\text { Renta gravable } \\
\text { (Estratos) }\end{array}$} & $\begin{array}{c}\text { Impuesto } \\
\text { base }\end{array}$ & $\begin{array}{c}\text { Porcentaje } \\
\text { Aplicable }\end{array}$ & \multicolumn{1}{c|}{$\begin{array}{c}\text { Sobre } \\
\text { exceso de }\end{array}$} \\
\hline De C\$ & Hasta C\$ & & & \\
1.00 & $75,000.00$ & 0 & $0 \%$ & 0.00 \\
$75,000.01$ & $100,000.00$ & 0 & $10 \%$ & $75,000.00$ \\
$100,000.01$ & $200,000.00$ & $2,500.00$ & $15 \%$ & $100,000.00$ \\
$200,000.01$ & $300,000.00$ & $17,500.00$ & $20 \%$ & $200,000.00$ \\
$300,000.01$ & $500,000.00$ & $37,500.00$ & $25 \%$ & $300,000.00$ \\
$500,000.01$ & a más & $87,500.00$ & $30 \%$ & $500,000.00$ \\
\hline
\end{tabular}

La estructuración de tales tablas rompe con la lógica de los principios de igualdad y capacidad contributiva por cuanto el término de comparación para diferenciar entre ambas tablas no es la capacidad contributiva de los sujetos, sino la calidad, en un caso, de "persona natural", y en el otro de "persona asalariada".

Ello va en contra de los postulados de estos principios, que exigen que los casos iguales desde el punto de vista del nivel de riqueza apta sean tratados de forma 
igual, y los desiguales de forma desigual, es decir, no se toma como término de comparación para hacer operativo el principio de igualdad el nivel de capacidad contributiva, con lo que se violan tales principios y los arts. 27, 48, y 114 de la Constitución.

\subsection{Supuestos de renta ocasional, art. 6 de la ley de equidad fiscal}

$\mathrm{El}$ art. 6 de la ley de equidad fiscal reformado estipula en su párrafo $3^{\circ}$ que "la renta ocasional y beneficios descritos en los párrafos anteriores están sujetos a retenciones en la fuente o a pagos a cuenta del IR anual, en la oportunidad, forma y monto que determine el Poder Ejecutivo en el ramo de hacienda...”

Tal disposición viola el principio de reserva de ley, que en el caso nicaragüense es absoluta, por cuanto el art. $114 \mathrm{Cn}$. estipula que la facultad de crear, modificar o derogar tributos es facultad exclusiva e indelegable de la Asamblea Nacional. Ahora bien, las retenciones en la fuente o pagos a cuenta del IR anual forman parte de la base imponible del IR anual, elemento de cuantificación que a la luz del artículo antes reseñado, más el $115 \mathrm{Cn}$. y aclarado por el art. $3 \mathrm{CTr}$. no puede ser determinado por el ramo de hacienda del poder ejecutivo. A mayor abundamiento pueden consultarse en este sentido la sentencia No. 5 de 2005 de la Sala de lo Constitucional de la Corte Suprema de Justicia de Nicaragua, y la sentencia No. 48 de la Corte Plena del mismo año.

\subsection{Pago mínimo definitivo}

La ley 712 reformó el art. 28 de la ley de equidad fiscal, el cual entró en vigencia en los siguientes términos:

Art. 28. Base imponible, alícuota del pago mínimo y forma de entero del pago mínimo

Para las personas referidas en el artículo anterior, el pago mínimo definitivo se liquidará sobre el monto de la renta bruta anual, de conformidad con el Artículo 5 de esta Ley, con la alícuota del uno por ciento (1\%). No formarán parte de la base imponible del pago mínimo, aquellos ingresos sobre los cuales se hubiesen efectuado retenciones definitivas.

El pago mínimo definitivo se realizará mediante anticipos del uno por ciento (1\%) de la renta bruta mensual. La industria fiscal y/o los responsables recaudadores del ISC, pagarán sus anticipos del IR en base a sus utilidades mensuales multiplicada por la alícuota del IR establecida en el numeral 1 del artículo 21 de esta Ley. En el caso de las personas naturales o jurídicas que 
obtengan, entre otras, rentas gravables mensuales en concepto de comisiones sobre venta o márgenes de comercialización de bienes y servicios, el anticipo del uno por ciento (1\%) de la renta bruta mensual, para estas últimas rentas, se aplicará sobre la comisión de venta o margen de comercialización obtenidos, siempre que el proveedor anticipe, como corresponde, el uno por ciento (1\%) sobre el valor total de la renta bruta mensual.

El principal escollo que encontramos en la redacción del presente artículo es la determinación del pago mínimo definitivo conforme a la renta bruta de los sujetos pasivos. Por definición acuñada en el art. 5 de la ley de equidad fiscal la renta bruta hace referencia, únicamente, a los ingresos de cualquier naturaleza que el contribuyente haya obtenido durante el año fiscal, sin que suponga tal concepto la deducción de los supuestos establecidos por la ley a efectos de definir la renta neta del sujeto pasivo.

$\mathrm{Al}$ gravarse la renta bruta del contribuyente, sin opción a deducción alguna por la ley, se está sometiendo a gravamen una manifestación de riqueza que no es capacidad contributiva, por cuanto no constituye una magnitud apta para el sufragio de los gastos públicos por no ser objeto de las deducciones necesarias para la creación de la riqueza, entre las que podemos mencionar, fundamentalmente, los gastos y costos inherentes a la producción de riqueza.

En este sentido, se está incidiendo en la fuente que crea la riqueza de forma directa, con lo que la regulación de este impuesto no sólo violaría el principio de capacidad contributiva en los términos del art. 114 Cn., sino que significaría también un supuesto confiscatorio al afectar directamente la fuente de riqueza sujeta a gravamen, según el dictado del art. $44 \mathrm{Cn}$. que protege la propiedad privada.

\section{Conclusiones}

1. La reforma tributaria 2009 operada a través de la ley 712 viola los principios de igualdad y capacidad contributiva referidos en los arts. 27, 48 y $114 \mathrm{Cn}$. en lo que toca a la regulación del impuesto sobre la renta de las personas físicas.

2. La reforma tributaria 2009 viola el principio de reserva de ley estipulado en los arts. 114 y $115 \mathrm{Cn}$. en lo que se refiere a la regulación jurídica de los supuestos de renta ocasional del art. 6 de la ley de equidad fiscal al habilitar al poder ejecutivo en el ramo de hacienda a determinar los supuestos de retención en la fuente y pagos a cuenta del IR. 
3. La reforma tributaria 2009 viola los principios de capacidad contributiva y no confiscatoriedad establecidos en los arts. 114 y $44 \mathrm{Cn}$. al someter a gravamen la renta bruta de los sujetos pasivos del pago mínimo definitivo regulado en el art. 28 de la ley de equidad fiscal reformada por la ley 712.

4. Le compete al legislador proceder a reformar los aspectos de la ley de equidad fiscal reformados en el año 2009 a través de la ley 712 por la violación expresa de los principios de justicia tributaria material y formal establecidos en la Constitución política de la República de Nicaragua.

5. Las modificaciones del ámbito tributario que le compete de forma exclusiva e indelegable a la Asamblea Nacional debe ser respetuosa de los principios de justicia tributaria establecidos por nuestra Constitución en los arts. 44, 114,115 y 138.27.

\section{Lista de referencias bibliográficas}

Abendroth, W. (1986). El Estado social. Madrid: Centro de Estudios Constitucionales.

Alexy, R., (2002a). Teoría de los Derechos Fundamentales. Madrid: Centro de Estudios políticos y constitucionales.

Alexy, R. (2002b). "Epílogo a la Teoría de los Derechos Fundamentales", Revista Española de Derecho Constitucional (66).

Alguacil Marí, Ma . P. (1999). "La capacidad económica como parámetro de enjuiciamiento", Revista de Derecho Financiero y Hacienda Pública (253).

Amatucci, A. (1965). L'Interpretazione della norma di Diritto Finanziario. Napoli: Jovene.

Amatucci, A. (1975). "Qualità della vita, interessi difussi e capacità contributiva". Rivista di Diritto Finanziario e Scienze delle Finanze (I).

Amatucci, A. (2001). Trattato di Diritto Tributario. Annuario.Padova: Cedam.

Amatucci, A. (2002). "Medidas para el Desarrollo Económico". XXI Jornadas Latinoamericanas de Derecho Tributario (I). Barcelona-Génova: AIDTL-ILADT. 
Amatucci, A. (2004). L'Ordinamento giuridico della finanza pubblica. Napoli: Jovene.

Balladares Saballos, R. (2002). "Compatibilidad entre el Principio de Capacidad Contributiva y los Fines Extrafiscales del Tributo”. XXI Jornadas Latinoamericanas de Derecho Tributario (Vol. I). Barcelona-Génova: AIDTL-ILADT.

Balladares Saballos, R. (2007). Código tributario de la República de Nicaragua. Managua: LEA.

Barberis, M. (2000). Filosofia del Diritto. Bologna: Il Mulino.

Barquero Esteban, J. M. (2002). La función del tributo en el Estado social y democrático de Derecho. Madrid: Centro de Estudios políticos y constitucionales.

Bernal Pulido, C. (2003). El principio de proporcionalidad y los derechos fundamentales. Madrid: Centro de Estudios Políticos y Constitucionales.

Bobbio, N. (1977). Dalla struttura alla funzione. Nuovi studi di teoria del diritto. Milano: Edizioni di Comunità.

Bobbio, N. (1984). "La funzione promozionale del Diritto rivisitata", Sociologia del Diritto ( XI/1984/3.

Böckenförde, E. W. (2000). Estudios sobre el Estado de Derecho y la democracia. (Traducción y Prólogo de Rafael de Agapito Serrano). Madrid: Trotta.

Canotilho, J.J. (1999). Direito Constitucional e Teoria da Constiuição. Coimbra: Livraría Almedina.

Carmona Cuenca, E. (1994). "El principio de igualdad material en la jurisprudencia del Tribunal Constitucional”, Revista de Estudios Políticos (84).

Carmona Cuenca, E. (2000). El Estado social de Derecho en la Constitución. Madrid: Consejo Económico y Social.

Casado Ollero, G. (1982). "El principio de capacidad y el control constitucional de la imposición indirecta (II)", Revista Española de Derecho Financiero (34). 
Cassese, S. (1990). "La finanza come strumento di azione dei poteri publici", Rivista di Diritto Finanziario e Scienza delle Finanze (I).

Cayón Galiardo, A. (1988). La unidad funcional de la Hacienda Pública. Madrid: IEF.

Cipollina, S. (1995). "Osservazioni sulla Politica Legislativa in materia fiscale", Rivista di Diritto Finanziario e Scienza delle Finanze (I).

Cossio Díaz J.R. (1989). Estado Social y Derechos de Prestación. Madrid: Centro de Estudios Constitucionales.

Cotarelo, R. (1990). Del Estado de Bienestar al Estado de Malestar. Madrid: Centro de Estudios Constitucionales.

Crisafulli, V. (1959). "Ancora in tema di eguaglianza", Giurisprudenza Costituzionale (1959) (pp. 745-750).

Crisafulli, V. (1965). "In tema di capacitá contributiva”, Giurisprudenza Costituzionale (1965) (pp. 857-890).

De Cabo Martín, C. (1986). La Crisis del Estado social. Barcelona: Promociones Publicaciones Universitarias.

De Juan Asenjo, O. (1984). La Constitución económica española. Madrid: Centro de Estudios Constitucionales.

Escribano López, F. (1989). Principio de igualdad y deber de contribuir en la Jurisdicción Constitucional. Madrid: IEF.

Ferreiro Lapatza, J. J. (2001). "Los elementos constitutivos de la obligación tributaria", en Amatucci, A. Tratado de Derecho Tributario (Dirigido por Andrea Amatucci). Bogotá: Temis.

Fichera, F. (1973a). Imposizione ed Extrafiscalità nel Sistema Costituzionale. Napoli: Edizioni Scientifiche Italiane.

Fichera, F. (1973b). "La giurisprudenza della Corte costituzionale sul tema dei rapporti tra imposizione ed extrafiscalità". Diritto e Pratica Tributaria (II).

Fichera, F. (2002). Le Agevolazioni Fiscali. Padova: Cedam. 
Gaffuri, G. (1969). L'attitudine alla contribuzione. Milano: Giuffrè.

Gallego Peragón, J. M. (2003). Los principios materiales de justicia tributaria. Granada: Comares.

García Etchegoyen, M. F. (2004). El principio de capacidad contributiva. Evolución dogmática y proyección en el Derecho argentino. Buenos Aires: Ábaco.

García-Pelayo, M. (1985). Las transformaciones del Estado contemporáneo. Madrid: Alianza Universidad.

Garrorena Morales, A. (1987). El Estado español como Estado social y democrático de Derecho. Madrid: Tecnos.

Gerloff, W. (1961). "Los impuestos: doctrina general" en Tratado de Finanzas, Tomo II, (Dirigido por GERLOFF, W. y NEUMARK, F.) Buenos Aires: Ateneo.

Giardina, E. (1961). Le basi teoriche della capacità contributiva. Milano: Giuffrè.

González Beilfuss, M. (2003). El principio de proporcionalidad en la jurisprudencia del Tribunal Constitucional. Pamplona: Aranzadi.

González García, E. (1993). La familia ante el fisco. Navarra: Rialp.

González García, E. (1996). Concepto actual de tributo: análisis de jurisprudencia. Pamplona: Aranzadi.

González García, E. \& Lejeune Valcárcel, E. (2000). Derecho Tributario I. Salamanca: Plaza Universitaria.

González Navarro, F. (1992). El Estado Social y Democrático de Derecho. Pamplona: Universidad de Navarra.

Guervós Má́llo, M. A. (2000). El Impuesto Balear sobre Instalaciones que Inciden en el Medio Ambiente. Madrid: Marcial Pons.

Herrera Molina, P. (1998). Capacidad económica y sistema fiscal. Análisis del ordenamiento español a la luz del Derecho alemán (Prólogo del Prof. Klaus Tipke). Madrid: Marcial Pons. 
Lago Montero, J. Ma. (2000). El Poder Tributario de las Comunidades Autónomas. Pamplona: Aranzadi.

Leibholz, G. (1984). Conceptos fundamentales de la política y de teoría de la Constitución. Madrid: Instituto de Estudios Políticos.

Lombardo, G. (1997). "Il principio di ragionevolezza nella giurisprudenza amministrativa", Rivista trimestrale di Diritto Pubblico, (4).

Lozano Serrano, C. (1990). Consecuencias de la jurisprudencia constitucional sobre el Derecho Financiero y Tributario. Madrid: Civitas.

Lucas Verdú, P. (1983). "Artículo 10", en Comentarios a las Leyes Políticas (Dirigidos pos Óscar Alzaga Villaamil) Tomo I. Madrid: Editoriales de Derecho Reunidas.

Maffezzoni, F. (1970). Il principio di capacità contributiva nel diritto finanziario. Torino: Utet.

Manzoni, I. (1965). Il principio della capacità contributiva nell'ordinamento costituzionale italiano. Torino: Giapichelli.

Martín Delgado, J. M. (1979), "Los principios de capacidad económica e igualdad en la Constitución española de 1978”, Hacienda Pública Española (6o) (pp. 72-93).

Martínez Tapia, R.(2000). Igualdady razonabilidaden lajusticia constitucional española. Almería: Universidad de Almería.

Micheli, G.A. (1967a). "Uguaglianza di trattamento, capacità contributiva e presunzioni di legge", en Scritti in Memoria di Antonio Giuffrè Vol. III. Milano: Giuffrè.

Micheli, G.A. (1967b). "Premesse per una teoria della potestà di imposizione". Rivista di Diritto Finanziario e Scienza delle Finanze (I).

Micheli, G.A. (1967c). "Capacitá contributiva reale e presunta”. Giurisprudenza Costituzionale (1967), (pp. 1525-1530).

Micheli, G.A. (1973). "Profili critici in materia di potestà di imposizione". Diritto e Pratica Tributaria (I). 
Micheli, G.A. (1975a). Curso de Derecho Tributario (traducción y estudio preliminar de Julio Banacloche). Madrid: Edersa.

Micheli, G.A. (1975b). "L' art. 20 della Costituzione e il potere di imposizione". Rivista di Diritto Finanziario e Scienza delle Finanze (I).

Moschetti, F. (1973). Il principio della capacità contributiva.Padova: Cedam.

Palao Taboada, C. (1980). Ordenanza Tributaria Alemana. Madrid: IEF.

Palao Taboada, C. (1988). "En torno a la jurisprudencia reciente del Tribunal Constitucional en materia financiera y tributaria”. Revista Española de Derecho Financiero (59).

Palao Taboada, C. (1995). "Los principios de capacidad económica e igualdad en la jurisprudencia del Tribunal Constitucional español”. Revista Española de Derecho Financiero (88).

Palao Taboada, C., (1976). "Apogeo y Crisis del Principio de Capacidad Contributiva”, en Estudios en Honor al Profesor Federico de Castro. Madrid: Tecnos.

Paulick, H. (1980). "Estudio Preliminar" a la Ordenanza Tributaria Alemana (Traducción de Carlos Palao Taboada). Madrid: IEF.

Pérez De Ayala, J. L. (1979). “Las cargas públicas: principios para su distribución”, Hacienda Pública Española (59).

Pérez De Ayala, J. L. (1997). Dinámica de la relación jurídico tributaria en el Derecho español. Madrid: Dykinson.

Prieto Sanchís, L. (1998). Ley, principios, derechos. Madrid: Dykinson.

Rodríguez Bereijo, A. (1992). "El sistema tributario en la Constitución (Los límites del poder tributario en la jurisprudencia del Tribunal Constitucional)". Revista Española de Derecho Constitucional (36).

Sainz De Bujanda, F. (1963). Hacienda y Derecho III. Madrid: Instituto de Estudios Políticos.

Tipke, K. (1977). “La ordenanza tributaria alemana de 1977”, Revista Española de Derecho Financiero (14). 
Tipke, K. (2002). Moral Tributaria del Estado y de los Contribuyentes. Madrid: Marcial Pons.

Vidal Marín, T. (2003). Un estudio sobre el deber de contribuir y los principios que lo informan: el artículo 31.1 CE. Valencia: Tirant Lo Blanch.

Vogel, K. (1968). "L’influsso della giurisprudenza della Corte Costituzionale sul Diritto Tributario vigente nella Repubblica Federale Tedesca". Rivista di Diritto Finanziario e Scienza delle Finanze (I).

Yebra Martul-Ortega, P. (2004). Constitución Financiera Española. Veinticinco años. Madrid: IEF. 


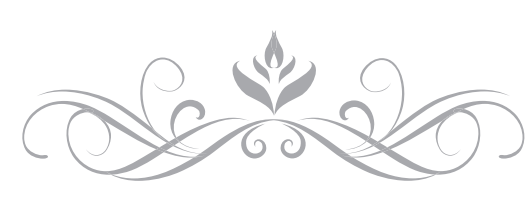

